\title{
O DAÍMON GREGO
}

\author{
Raphael Felipe Cordeiro*
}

\begin{abstract}
RESUMO
O tema presente artigo é a exposição da personagem daímon evidenciada em três períodos temporais distintos na cultura Grega, sendo representada essa divisão por três autores literários: 0 poeta Hesíodo, entre os séculos VIII e VII a.C.; o filósofo Empédocles, do século $\mathrm{V}$ a.C. e o filósofo Platão, entre o século IV e III a.C.. 0 resultado indica que o daímon perpassa na literatura dos três autores, o que demonstra uma cultura desenvolvida ao daímon.
\end{abstract} Palavras-chave: Daímon. Hesíodo. Empédocles. Platão

\begin{abstract}
The theme of this article is the exposition of the character from that time, evidenced in three diferente time periods in Greek culture, with this Division being represented by three literary authors: The poet Hesiod, betwenn the 8th and 7 th centuries b.C; The philosopher Empedokle, from the 5th century b.C. and the philosopher Plato, betwenn the 4th and 3rd centuries b.C. The result indicates that the lámonon permeates in the literature of the three authors, which demonstrates a culture developed to the daímon.
\end{abstract}

Keywords: Daímon. Hesiod. Empedokle. Platon

\section{INTRODUÇÃO}

0 presente artigo científico é fruto de um recorte de um trabalho de conclusão de curso, conforme a investigação sobre a personagem

* raphaelfelipecordeiro@gmail.com 
daímon na cultura Grega estava sendo demasiadamente explorada, percebeu-se a necessidade de uma outra abordagem e com isso tornou-se um outro objeto a ser investigado. 0 que torna como objeto deste artigo uma exposição da personagem daímon de acordo com uma leitura filosófica através de três autores: Hesíodo, Empédocles e Platão. Para o desenvolvimento deste artigo foi realizado um estudo das obras dos autores com comentários de Plutarco, Burnet, Pereira e outros. 0 presente artigo é especialmente motivado, pela profundeza de detalhes diante da tentativa de compreender a personagem daímon e sua relação com a cultura Grega, levanta-se a hipótese que haveria uma cultura da figura daímon que se manteve em períodos diferentes, evidenciando nas obras literárias entre os autores escolhidos para análise e que durante a análise poderá ser identificada.

\section{O Daímon Grego}

O título "O daímon grego" foi escolhido cuidadosamente para oferta com a ideia de desprender da expressão "daímon socrático" ou o daímon de Sócrates, do que talvez seja a expressão mais difundida contemporaneamente na história da filosofia. Não que será negado, mas que a personagem daímon, se for permissível assim afirmar, o culto ao daímon, estaria associado a cultura Grega arcaica em geral, ou é o que pelo menos tentará ser expostos no decorrer da análise.

Segundo Darcus (1977, pp. 185-186) a palavra daímon "deriva da raiz dai-, com o significado de 'dividir' ou 'distribuir'.". Para Peters (1967, p. 18) daímon é "presença ou entidade sobrenatural, algures entre um deus e um herói" e "estaria na cultura Grega em que a crença em espíritos sobrenaturais um pouco menos antropomorfizados do que os Olímpicos é uma característica muito recuada da religião popular Grega; um certo daímon está ligado a uma pessoa entre o nascimento e sua morte, para o bem ou para o mal, conforme o seu destino [...]". A evidência de que o daímon está associado a uma natureza divina é unânime aos autores nomeados na pesquisa, porém, para cada autor terá aspectos distintos que serão expostos posteriormente.

A figura da personagem daímon está presente na literatura filosófica podendo ser encontrada nas mais diversas obras: No fragmento 
119 de Heráclito; Nas Memoráveis de Xenofonte no Livro 1, 1 - 4); Em Cicero (De Natura Deorum 3, 17); No Pseudo-Hyginus (Prefácio); Em Marco Aurélio (II, 17, III, 16); E claro, Platão (Apologia 21-b, 33-c; Críton 44a; Fédon 60c); acredita-se que obteve o objetivo alcançado na intenção de demonstrar a diversidade da presença da personagem na literatura, já que uma exposição completa - se fosse possível - seria fora de propósito.

Denúnciar uma originalidade Grega para a criação da personagem daímon torna-se um trabalho arqueológico inviabilizado, sabendo-se que a tradição poética tem sua origem na oralidade acaba tornando dificil a localização e a identificação do processo de construção da originalidade Grega. Quando confrontado as fontes gregas, haveria uma percepção de outras culturas: sendo elas semítica, conforme Peters (1967, p. 18) denúncia sobre uma omissão por parte de Plutarco em que: "uma fonte omitida por Plutarco é o contacto com a tradição semítica”. O filósofo Fílon de Alexandria irá identificar sua origem como os anjos da tradição judaica nas obras: Dos Sonhos 141-142 e Sobre os Gigantes 6-9. Talvez o que se tem como o daímon seria uma espécie de "pensamento-rizoma", um termo de Deleuze e Guatarri (2011). A metafora do rizoma consiste: em que estando o sujeito apenas percebendo o objeto de pesquisa, no caso o daímon na grecia antiga, estaria analisando apenas o que está exposto, como um rízoma ${ }^{1}$ e ao escavar encontramos um complexo de canais interligados uns aos outros, igual a forma do rízoma na ciência biológica, onde cada canal representa a contibuição dessas culturas na formação deste único objeto amostra, no entanto, de alguma forma todos conectados. O que torna difícil compreender se haveria uma linealidade de efeitos para construção da cultura ao daímon.

Existe uma diferença temporal entre os três autores, o que poderia haver semelhança entre algumas ideias ou até mesmo na linguagem empregada por ambos, uma comparação entre as três obras poderia induzir que tanto Empédocles quanto Platão conhecesse diretamente os poemas de Hesíodo; já que Empédocles viveu aproximadamente no século V a.C., Platão viveu aproximadamente entre o século IV e III a.C.

1 Raiz; Tubérculo; Talo ou Ramo.

Revista Páginas de Filosofia, v. 9, n. 2, p. 59-68, jul.-dez. 2020 
e Hesíodo antecedendo-os, entre os séculos VIII e VII a.C.. Entretanto, Platão e o acragantino poderiam ter originado seus conhecimentos de outra fonte; por exemplo, um poeta que estaria apenas reproduzindo Os Trabalho e os Dias. Outra possibilidade é que tanto Hesíodo como Empédocles e Platão partilhava da mesma fonte da qual extraíram parte do material para construção dos seus pensamentos. A hipótese de uma cultura a figura daímon surge dessa possível influência narrativa que haveria na grécia como destacou Peters $(1967$, ibid.) "estaria na cultura Grega”, é uma figura no imaginário grego que vai se transformando entre conforme a passagem do tempo e obras literárias, sendo ora: figurante (Hesíodo), protagonista (Empédocles) e coadjuvante (Platão).

\section{O DaÍMON EM Hesíodo}

Segundo Plutarco, Hesíodo foi o primeiro que difundiu melhor a personagem daímon, expondo-a como um ser transitório entre os deuses e os herói.

Mas Hesíodo foi o primeiro que se saiu melhor e mais distintamente estabeleceu quatro naturezas razoáveis, os Deuses, os Daemons (sendo muitos em número e bons em sua espécie), heróis e homens; pois os semideuses são contados entre os heróis. Outros dizem que há uma transmutação tanto dos corpos quanto das almas; e que, assim como vemos da terra é engendrada a água, da água o ar, e do ar fogo, a natureza da substância ainda ascendendo mais alto, assim, os bons espíritos sempre mudam para melhor, sendo transformados de homens em heróis, e de heróis em Daemons; e dos Daemons, aos poucos e em um longo espaço de tempo, algumas almas sendo refinadas e purificadas vêm a participar da natureza da Divindade. Mas há alguns que não conseguem se conter, mas vagam até serem enredados em corpos mortais, onde vivem mesquinha e obscuramente, como fumaça. (Plutarco, 1874, p. 15)

O papel do daímon hesiódico demonstra-se um espécie de mensageiro, um condutor entre o Deus e o Homem e vice-versa. É através da poesia Os trabalhos e os dias que Hesíodo irá nomear essas características em: 
Os homens que viviam na idade do ouro, após o término no período destinado a eles, foram transformados por desígnios de Zeus em daímones, espécie de protetores dos mortais, para vigiarem as suas decisões e, em alguns casos, distribuirem riquezas. (DK 4 Os trabalhos e os dias - vs. CXX- CXXVI)

Por mais que a natureza dos daímones em Hesíodo sejam de criar uma comunicação entre os deuses e os homens, ainda há uma subordinação exclusiva por parte da divindade, o daímon obedece por uma ordem divina mesmo sendo um cuidador dos mortais.

\section{O DAímON EM EMPÉdoCLES}

Na cosmogonia de Empédocles os seres viventes são compostos, decompostos e recompostos através dos movimentos de elementos da natureza (fogo, terra, água e ar) causadas pelas forças primordiais do Amor (Philotes) e do Ódio (Neîkos). Quando Empédocles estabelece a causa de movimento nas figuras de Philotes e Neîkos estaria ele talvez sendo influenciado pela crença do culto ao daímon. Pereira (2006, p. 157) "Ambos, esses daímones, são divinos e "expressariam" phília e neîkos." A princípio a nomeação dos daímones como forças de movimento de aproximação e afastamento poderia ser o indício que ligaria a personagem daímon, pois poderá ser encontrado na poesia de Hesíodo uma larga lista dos daímones ${ }^{2}$, entre eles Philotes e Neîkos.

Entretanto, na filosofia de Empédocles ocorre uma outra concepção, o daímon seria um outro nome dado para alma e que através de uma conduta (de acordo com a natureza do seu daímon) poderia ser libertado, conforme Burnet:

De acordo com um decreto da Necessidade [anánke], os "demônios" [daimónion] que pecaram são forçados a vagar para longe de sua casa celestial por três vezes 10 mil estações (frag. 115). 0 próprio Empédocles é uma dessas divindades exiladas e decaiu de sua posição elevada por ter depositado confiança na delirante Discórdia. (Burnet, 2006, p. 253)

2 DK4 B Teogonia vs. CXL - CXCV

Revista Páginas de Filosofia, v. 9, n. 2, p. 59-68, jul.-dez. 2020 
Havendo uma afirmação por parte de Empédocles (DK31B CXV) como um daímon: "A estes também, agora, pertenço eu, um banido dos deuses, errante, por ter confiado no furioso Ódio.".

\section{O Daímon Socrático}

Na personagem Sócrates haverá duas fontes distintas da natureza do daímon socrático: Uma em Xenofonte em "e até por duas vezes, já, tentei ocupar-me da minha defesa, mas a divindade [daímon] não me permitiu." (2008, Mem. I, 1, 4) e outra em Platão "começou de menino, uma voz que me vem, que quando vem é sempre para me dissuadir de fazer aquilo que estou prestes a fazer (jamais para me persuadir)" (2007, Apologia de Sócrates, 31d). Enquanto uma tem uma natureza de persuadir o que deve ser feito (Xenofonte), a outra tem uma natureza contrária, a de persuadir o que não-deve ser feito (Platão), contudo, em ambas temos o daímon sempre como um condutor, uma espécie de guia espiritual. Na República encontra-se uma explicação que antes do nascimento haveria uma escolha da vida que seria levada ao reencarna- $\mathrm{se}^{3}$, essa vida seria acompanhada pelo daímon a fim de fazer cumprir-se a decisão tomada:

"Palavras da virgem Láquesis, filha da Necessidade! Almas efêmeras, agora é o começo de outro período portador da morte para a raça mortal. Não será um dêmon que vos sorteará, mas vós que escolhereis um dêmon. Que o primeiro sorteado seja o primeiro a escolher a vida a que estará ligado pela necessidade. A virtude não está sob nenhum senhor. Honrando-a ou desprezando-a, cada um dela obterá mais ou menos. A responsabilidade é de quem escolhe, o deus é isento de culpa". (Platão, República, Livro X 620-e)

Mas é em outro diálogo platônico que estabelece uma explicação mais aprofundada da figura do daímon. No Banquete, após todos discursarem sobre o que é o amor, a sacerdotisa Diotima revelará a natureza de Eros em:

3 Para esse processo é dado o nome de metempsýchôsis (Transmigração das almas), conforme Peters (1967, p. 112). 
[Diotima] “ 'Mas no entanto, o Amor, tu reconheceste que, por carência do que é bom e do que é belo, deseja isso mesmo que é carente.'

[Sócrates] “' 'Reconheci, com efeito.'

[Diotima] " 'Como então seria deus o que justamente é desprovido do que é belo e bom?'

[Sócrates] “'De modo algum, pelo menos ao que parece.'

[Diotima] “' Estás vendo então', disse, 'que também tu não julgas o Amor um deus?'

[Sócrates] “'Que seria então o Amor?', perguntei-lhe. 'Um mortal?'

[Diotima] " 'Absolutamente.'

[Sócrates] “'Mas o quê, ao certo, ó Diotima?'

[Diotima] " 'Como nos casos anteriores', dissem ela, 'algo entre mortal e imortal.'

[Sócrates] “'O quê, então, ó Diotima?'

[Diotima] “ 'Um grande gênio [daimon], ó Sócrates; e com efeito, tudo o que é gênio [daimon] está entre um deus e um mortal.'

[Sócrates] " 'E com que poder?', perguntei-lhe.

[Diotima] " 'O de interpretar e transmitir aos deuses o que vem dos homens, e aos homens o que vem dos deuses, de uns as súplicas e os sacríficios, e dos outros as ordens e as recompensas pelos sacrifícios; e como está no meio de ambos ele os completa, de modo que o todo fica ligado todo ele a si mesmo. Por seu intermédio é que procede não só toda arte divinatória, como também a dos sacerdotes que se ocupam dos sacrifícios, das iniciações e dos encantamentos, e enfim de toda adivinhação e magia. Um deus com um homem não se mistura, mas é através desse ser que se faz todo o convívío e diálogo dos deuses com os homens, tanto quando despertos como quando dormindo; e aquele que em tais questões é sábio é um homem de gênio [daimon], enquanto o sábio em qualquer outra coisa, arte ou ofício, é um artesão. E esses gênios [daimon], é certo, são muitos e diversos, e um deles é justamente o Amor. (Banquete, 202d-203a)

Ao defrontar com a natureza do daímon-Eros poderia teorizar através do pensamento de Acker (2013, p. 126), que Sócrates ao interagir com um daímon, estaria interagindo com o próprio Eros, em:

Eros é o filho de Poros e de Pênia, riqueza e penúria, mas é graças à sua mãe e não a seu pai que Eros possui sua mais importante característica: a carência, reforçando a importância da herança materna no mito de sua origem. Por outro lado, é notável que a iniciativa da concepção seja 
tomada pela mãe de Eros, enquanto Poros está dormindo. 0 papel ativo da mãe e a transmissão da linhagem matrilinear são assim destacados, contrariando a valorização da reprodução dos traços do pai na prole, tão desejado pelos homens gregos. Sobre esse aspecto, devemos pensar no próprio Sócrates, cujo pai era um escultor e a mãe, uma parteira. Ele assume o papel da mãe ao se designar como parteiro de almas, dando à Filosofia o status de um parto. 0 modelo de Sócrates é a mãe, pois ele nunca comparou a Filosofia a um trabalho de escultura. (Acker, 2013, p. 126)

Poderá deduzir por um príncipio de verossimilhança que Sócrates, de acordo com Platão, seria também um outro daímon na medida em que torna-se consciente de sua existência.

O mito do daímon, segundo as considerações levantadas apenas nesta análise, esta sustentado através de um processo evolutivo da alma em que todos os seres viventes, tornando-se ciente do seu estado temporário e seguindo conforme sua natureza, poder-se-iam com o rompimento no processo transmigatório da alma. 0 que tornaria, se a indicação da análise estiver correta, um problema ético, pois nem todos os daimones teriam sua orígem fundamentada no supremo bem. É o que indicará Plutarco (Do Defeitos dos Oráculos, 1874, p. 23-24) que "não é apenas Empédocles que afirma que existem maus Daemons, mas até mesmo Platão, Xenócrates e Crisipo; sim, e Demócrito, quando ele orava, ele podia encontrar bons espíritos, o que mostra que ele pensava que havia maus e bons Daemons". É possível que as questões éticas já foram alvo de crítica dos epicureus:

Mas quanto ao que eu ouvi os epicureus alegarem contra os Daemons que Empédocles traz, - como, que é impossível que eles possam ser felizes e ter uma vida longa se forem afetados de forma perversa e cruel, porque o vício em sua própria natureza é cego e naturalmente se precipita em travessuras como destruir a vida - isso, devo lhe dizer, é vão e ocioso. (Plutarco, Do defeito dos Oráculos, 1874, p. 26)

E o que ressalta-se é que haveria uma diversidade de daimones, denominados por almas, atribuídos cada qual a uma natureza e sendo eles responsáveis pelo movimento dos corpos. Cada ser é uma potência 
no processo evolutivo do mito do daímon conforme sua obediência e sua ciência do seu estado como ser vivente.

\section{Considerações FinAis}

A personagem daímon é explorada por todos os autores o que se deduz que havería uma cultura pautada na figura do daímon. Mas há particularidades em determinadas características, como foi demonstrada. Em Hesíodo, o daímon aparece como um ser divino, transformado pela vontade de Zeus a servir como mensageiro entre os deusdes e os mortais. Em Empédocles, é a própria alma dos mortais, aprisionados no processo de composição, decomposição e recomposição. E em Platão, ele aparece como um gênio escolhido pelo próprio mortal ao reencarnar, compelido a conduzir a natureza humana que foi designado.

Embora a hipótese apresentada foi atendida, havendo a demonstração da ligação da personagem daímon entre os três autores, não esgota a possibilidade de uma profundidade de análise sobre o tema. Criando assim, novas hipóteses: poderia ser considerado um culto ao mito daímon? Quais impactos sociais foram absolvidos pela cultura do daímon? Qual a relevância da figura do daímon ser resgatada nos diálogos platônicos?

O que demonstra a riqueza da cultura Grega sendo inesgotável objeto de pesquisa ao perceber as influências e as mutações do pensamento para um determinado objeto de estudo. 0 daímon demonstrou uma mutação da passagem de um ser externo do sujeito para um o ser do sujeito, o que torna uma reflexão talvez plausível de salientar, que o daímon poder-se-ia ser a relação que o sujeito tinha com o próprio pensamento transformando-o em um ser independente na medida de sua interessão, conforme o sujeito refletia sobre si poderia estar interagindo com o seu próprio pensamento como se fosse um diálogo com um outro ser, um ser intangível que acompanha e que direciona a natureza do sujeito, tal como ele é, o que podemos definir e exemplificar na contemporaneidade como o exame de consciência. 


\section{REFERÊNCIAS}

ACKER, Clara. Femmes, Fêtes et philosophie en Grèce ancienne. Paris: L'Harmattan, 2013.

BURNET, John. A aurora da filosofia grega. (Vera Ribeiro, Trad.) Rio de Janeiro: PUC-Rio, 2006.

DARCUS, Shirley M. Daimon Parallels the Holy Phren in Empedocles. Phronesis, vol. 22, no 3, 1977, pp. 175-190. JSTOR, Disponível em: <www.jstor.org/stable/4182016>. Acesso em: 13 Ago. 2020.

DELEUZE, Gilles; GUATARRI, Félix. Mil Platôs - Vl. 1: Capitalismo e esquizofrenia 2. São Paulo: Editora 34, 2011.

EMPÉDOCLES. Fragments In: Os Pré-Socráticos (José Cavalcante de Souza, Trad.) São Paulo: Nova Cultural, 1996.

HESÍODO. Teogonia. (Jaa Torrano, Trad.) São Paulo: Iluminuras, 2012.

____. Os trabalhos e os dias. (Alessandro Rolim de Moura, Trad.) Curitiba: SEGESTA, 2012.

Teogonia. (Christian Werner, Trad.) São Paulo: Hedra, 2013.

JAEGER, Werner. Paidéia. (Arthur M. Parreira, Trad.) São Paulo: Martins Fontes, 1995. PEREIRA, Ivanete. Aspectos sagrados do mito e do lógos. São Paulo: PUC-SP, 2006. PETERS, Francis Edward. Termos Filosóficos Gregos: um léxico histórico. (Beatriz Rodrigues Barbosa, Trad.). Lisboa: Fundação Calouste Gulbenkian, 1967.

PlATÃo. A República. (Anna Lia A. A. Prado, Trad.) São Paulo: Editora Martins Fontes, 2014.

O Banquete. (José Cavalcante de Souza, Trad.) São Paulo: Editora 34, 2016.

Apologia de Sócrates. (A. Malta, Trad.) São Paulo: L\&PM Pocket, 2017.

PLUTARCO. Morais de Plutarco. Tradução multipla revisada por William W. Goodwin. Cambridge: Imprensa de John Wilson e Filho, 1874.

XENOFOnTE. Apologia de Sócrates. (Ana Elias Pinheiro, Trad.) Coimbra: Centro de Estudos Clássicos e Humanísticos, 2008. 